University of Nebraska - Lincoln

DigitalCommons@University of Nebraska - Lincoln

Sociology Department, Faculty Publications

Sociology, Department of

\title{
$5-2011$
}

\section{Women's Sexual Orientations and Their Experiences of Sexual Assault Before and During University}

\author{
Sandra L. Martin \\ University of North Carolina, Chapel Hill, sandra_martin@unc.edu \\ Bonnie S. Fisher \\ University of Cincinnati, bonnie.fisher@uc.edu \\ Tara D. Warner \\ University of Nebraska-Lincoln, twarner2@unl.edu \\ Christopher P. Krebs \\ RTI International, Research Triangle Park, North Carolina, krebs@rti.org \\ Christine $\mathrm{H}$. Lindquist \\ RTI International, Research Triangle Park, North Carolina, lindquist@rti.org
}

Follow this and additional works at: https://digitalcommons.unl.edu/sociologyfacpub

Part of the Criminology Commons, Criminology and Criminal Justice Commons, Gender and Sexuality Commons, and the Social Control, Law, Crime, and Deviance Commons

Martin, Sandra L.; Fisher, Bonnie S.; Warner, Tara D.; Krebs, Christopher P.; and Lindquist, Christine H., "Women's Sexual Orientations and Their Experiences of Sexual Assault Before and During University" (2011). Sociology Department, Faculty Publications. 197.

https://digitalcommons.unl.edu/sociologyfacpub/197

This Article is brought to you for free and open access by the Sociology, Department of at DigitalCommons@University of Nebraska - Lincoln. It has been accepted for inclusion in Sociology Department, Faculty Publications by an authorized administrator of DigitalCommons@University of Nebraska - Lincoln. 


\title{
Women's Sexual Orientations and Their Experiences of Sexual Assault Before and During University
}

\author{
Sandra L. Martin, $\mathrm{PhD},{ }^{1}$ Bonnie S. Fisher, $\mathrm{PhD},{ }^{2}$ Tara D. Warner, $\mathrm{MA},{ }^{3}$ \\ Christopher P. Krebs, $\mathrm{PhD},{ }^{4}$ and Christine H. Lindquist, $\mathrm{PhD}^{4}$ \\ 1. Department of Maternal and Child Health, Gillings School of Global Public Health, \\ University of North Carolina, Chapel Hill, North Carolina \\ 2. School of Criminal Justice, University of Cincinnati, Cincinnati, Ohio \\ 3. Department of Sociology, Bowling Green State University, Bowling Green, Ohio \\ 4. RTI International, Research Triangle Park, North Carolina
}

Corresponding author - Sandra L. Martin, Department of Maternal and Child Health, CB\#7445, Gillings School of Global Public Health, University of North Carolina, Chapel Hill, NC, 27599-7445; tel 919 966-5973, fax 919 966-0458, email sandra_martin@unc.edu

\begin{abstract}
Purpose - We sought to examine relationships between women's sexual orientations and their sexual assault experiences before and during university.

Methods - Self-reported responses on a web-based survey of 5,439 female undergraduates who participated in the Campus Sexual Assault study were analyzed to compare three groups: bisexuals, lesbians, and heterosexuals. Groups were compared in terms of the prevalence of sexual assault before and during university, and the extent to which sexual assault before university predicted sexual assault during university.

Findings - The prevalence of sexual assault before and during university was higher among bisexuals and lesbians compared with heterosexuals $(25.4 \%$ of bisexuals, $22.4 \%$ of lesbians, and $10.7 \%$ of heterosexuals were sexually assaulted before university; $24.0 \%$ of bisexuals, $17.9 \%$ of lesbians, and $13.3 \%$ of heterosexuals were sexually assaulted during university). Sexual assault before university was highly predictive of sexual assault during university, especially among non-heterosexuals. Compared with heterosexuals not sexually assaulted before university (the referent group), previously assaulted non-heterosexuals (bisexuals/lesbians) had eight times the odds of sexual assault during university (adjusted odds ratio $[\mathrm{AOR}]=8.75$ ), whereas previously assaulted heterosexuals had four times the odds of sexual assault during university (AOR, 4.40). However, there was no difference in the odds of sexual assault during university between non-heterosexuals not sexually assaulted before university and heterosexuals not sexually assaulted before university.

Conclusion - Bisexual and lesbian women are more likely than heterosexual women to be sexually assaulted before and during university. Sexual assault before university is linked to sexual assault during university for all women, with this association being especially pronounced among non-heterosexuals.
\end{abstract}

\section{Introduction and Background}

One in six women in the United States experiences attempted or completed rape (Tjaden \& Thoennes, 2000). Such assaults result in injuries, as well as physical and mental health problems that may continue for many years (Bonomi et al., 2007; Campbell and Wasco, 2005; Demaris and Kaukinen, 2005; Martin et al., 2008, 2011; Stockman et al., 2010; Sugar et al., 2004). More than half of U.S. rape victims are younger than 18 years old when first sexually assaulted (Tjaden \& Thoennes, 2000). Women continue to be at high risk for sexual victimization during young adulthood, with one fifth to one quarter of female students being raped/sexually assaulted during their university tenure (Fisher et al., 2000; Krebs et al., 2007, 2009a).

A growing body of research documents high rates of sexual assault among university students (Banyard et al., 2007; Fisher et al., 2000; Howard et al., 2008; Kilpatrick et al., 2007; MohlerKuo et al., 2004), and a complimentary body of research doc- 
uments high rates of sexual assault among sexual minority groups in the general (non-student) population (Balsam et al., 2005; Dunbar, 2006; Greenwood et al., 2002; Heidt et al., 2005; Heintz and Melendez, 2006; Houston and McKirnan, 2007; Hughes et al., 2010; Kimerling et al., 2002; Long et al., 2007; Ratner et al., 2003; Samandari and Martin, 2010); however, little research has examined how sexual orientation influences university students' experiences of sexual assault. One university-based study that did examine links between students' sexual orientations and sexual assault surveyed 412 female and male Illinois undergraduates, and found that non-heterosexuals (bisexuals, lesbians, and gays) had a significantly higher lifetime prevalence of sexual victimization than heterosexuals (Duncan, 1990). A Yale survey found that $9 \%$ of 97 bisexual, lesbian, or gay undergraduates reported experiencing sexual harassment/assault while at Yale because someone assumed they were lesbian/gay (Herek, 1993). Evaluation of a sexual assault prevention program implemented with freshman at a Northeastern university found that, both within the intervention and comparison groups, greater percentages of non-heterosexuals (bisexuals, lesbians, and gays) than heterosexuals experienced sexual assault before and after the intervention (Rothman \& Silverman, 2007).

These few studies of relationships between university students' sexual orientations and their sexual assault experiences have enhanced our knowledge concerning this important topic; however, these studies have some methodologic limitations. Although sexual assault risk is greater among females than males, previous analyses have not always stratified by respondents' gender, disallowing examination of the impact of sexual orientation on the higher-risk group, specifically, females. Moreover, past investigations have often examined small, convenience samples of students, rather than large student samples from all years of higher education study. In addition, previous research has typically asked about sexual assault experiences that occurred either during the students' entire lifetimes or during a specific year in school, rather than asking specific questions about sexual assault that occurred before the respondent began university and additional questions about that which occurred while the respondent was attending university. Therefore, past research is not able to describe whether sexual orientation has a differential effect on sexual assault experiences before and during university. Finally, previous investigations have often only examined sexual assault in general or one type of sexual assault, rather than examining different types of sexual assault (such as physically forced sexual assault and incapacitated sexual assault). Among the reasons that it is important to understand the relationship between sexual orientation and specific types of sexual assault is because different risk factors have been associated with different types of sexual assault (Krebs et al., 2009b).

The current study extends past research to enhance our understanding of the relationship between university women's sexual orientations and their experiences of sexual assault by studying a sample of 5,439 female undergraduates from two universities. Three groups of women-bisexuals, lesbians, and heterosexuals - are compared in terms of:

1. Race/ethnicity, age, university attended, and year of study;

2. The prevalence of two types of sexual assault (specifically, physically forced sexual assault and incapacitated sexual assault) before entering university and during university; and
3. The degree to which sexual assault before university predicts sexual assault during university.

\section{Methods}

\section{Sample and Recruitment}

This research uses data from the Campus Sexual Assault (CSA) study (Krebs et al., 2007, 2009a, 2009b), an investigation of the sexual assault experiences of undergraduates at two U.S. public universities. These universities were selected for study because the research team had contacts at these universities who could help facilitate the recruitment of student participants.

One study university is in the Southeast and the other is in the Midwest. The Southeastern university had approximately 15,600 undergraduate students at the time of this research, with approximately $80 \%$ being from the state in which the university is located. This school admits approximately one third of its undergraduate applicants, with approximately $40 \%$ of those admitted being ranked tenth or higher in their high school graduating class. The Midwestern university had approximately 19,512 undergraduate students at the time of this research, with approximately $90 \%$ being from the state in which the university is located. This school admits approximately $75 \%$ of its undergraduate applicants, with approximately $20 \%$ of those admitted being ranked tenth or higher in their high school graduating class.

Within each school, a stratified random sample of undergraduates (aged 18-25) enrolled at least three quarters time was selected. Stratification variables included students' school, year of study, and gender.

Selected students were recruited via e-mail during fall 2005 and winter 2006. The e-mail invited students to participate in a web-based survey that "asks about your experiences with student life, drugs and alcohol, sexual activity, and sexual assault." This e-mail provided each student with a unique identification number used first to access and complete the survey, and then to access a $\$ 10$ on-line vendor gift card (the incentive for participation). Each identification number could be used to access only one survey and one incentive. This approach was chosen as the means of data collection for a number of reasons, including university students' familiarity and comfort with computerized surveys, privacy of student e-mail accounts (unlike traditional mail to residences that could be received by roommates, etc.), and the ease and low cost of administration.

A total of 12,836 undergraduate women were e-mailed the invitation to participate in the study. Of these, $5,446(42.2 \%$ in one university and $42.8 \%$ in the other university) responded to the survey and answered the sexual assault questions. Comparison of these respondents and nonrespondents on a variety of variables (university, year of study, age, and race/ethnicity) found only one statistically significant difference, specifically that non-White students (i.e., Black, Hispanic, or other) were slightly less likely than White students to respond. A generalized exponential model was used to create weights to adjust the data for nonresponse by race/ethnicity, as well as by university, year of study, and age (Folsom \& Singh, 2000). Using these weights reduced the observable bias, indicated by Cohen's effect size, to negligible levels (Cohen, 1988). This report focuses on 5,439 (99\%) of these 5,446 female CSA survey respondents, specifically, those who also answered the survey question concerning sexual orientation. 


\section{Assessment}

The CSA survey examined a range of topics, including the students' sexual orientations. Students were asked, "Which of the following best describes your sexual orientation?" with response options including "heterosexual/straight," "lesbian/ gay," and "bisexual."

The survey explained that the study was interested in students' experiences with "nonconsensual or unwanted sexual contact," defined to include forced touching, oral sex, vaginal sexual intercourse, anal sexual intercourse, and vaginal or anal penetration with a finger/object committed by any type of person (strangers or someone known to the respondent, such as a family member or dating partner). Students were then asked about two types of sexual assault: Physically forced sexual assault and incapacitated sexual assault. Physically forced sexual assault was assessed by asking "Has anyone had sexual contact with you by using physical force or threatening to physically harm you?" with separate questions asked for two time periods: before entering college and since entering college. Students' experiences of incapacitated sexual assault were assessed by asking "Has someone had sexual contact with you when you were unable to provide consent or stop what was happening because you were passed out, drugged, drunk, incapacitated, or asleep?" with separate questions covering the two time periods. This paper focuses on these two forms of completed sexual assault, which were the primary outcomes of the CSA study: physically forced sexual assault and incapacitated sexual assault. The CSA survey also collected information about the characteristics of the students, including their year of study, age, and race/ethnicity.

\section{Statistical Analysis}

Descriptive statistics and bivariate analyses were used to compare the women of the three sexual orientations in terms of several characteristics (race/ethnicity, age, university attended, and year of study). Prevalence estimates and associated $95 \%$ confidence intervals (CIs) were used to examine the extent of physically forced sexual assault and incapacitated sexual assault experienced by women in each of the three groups, both before entering university and during university. Prevalence ratios and associated 95\% CIs (Thompson, Myers, \& Kriebel, 1998) were used to compare the prevalence of each type of sexual assault (before and during university) among bisexuals relative to heterosexuals and among lesbians relative to heterosexuals.

To examine whether women's experiences of sexual assault before university were predictive of their experiences of sexual assault during university, for each of the three sexual orientation groups, the percentage of women who experienced sexual assault during university was examined, stratified by whether or not the women had experienced sexual assault before university. The differences in these proportions were tested using $z$-tests.

Logistic regression models examined associations between women's experiences of sexual assault before university and their experiences of sexual assault during university, taking into consideration sexual orientation and other variables. A logistic regression model estimated the odds of women having experienced any type of sexual assault during university (yes vs. no) as a function of women's sexual orientations and experiences of sexual assault before university. Three indicator vari- ables defined four groups of interest: 1) bisexuals and lesbians with sexual assault before university, 2) bisexuals and lesbians without sexual assault before university, 3) heterosexuals with sexual assault before university, and 4) heterosexuals without sexual assault before university (the referent group). Bisexuals and lesbians were grouped together for this analysis to generate adequate statistical power and because (as will later be described) bivariate analyses found that these two groups were quite similar in terms of their sexual assault experiences. This logistic regression analysis included several control variables, including race/ethnicity (non-Hispanic White vs. all other racial/ethnic groups as the referent group), age ( $\geq 21$ vs. $18-20$ as the referent group), university attended (Southeastern vs. Midwestern as the referent group), and year of study (junior or senior vs. freshman or sophomore as the referent group). Estimated adjusted odds ratios (AORs) and corresponding 95\% CIs were computed to make comparisons among the women of differing sexual orientations and histories of sexual assault, while taking into consideration the control variables.

Analyses used response data weighted by means of a generalized exponential model to adjust for nonresponse bias as previously described (Folsom \& Singh, 2000). SAS software, version 9.1, of the SAS System for Windows (SAS Institute, Inc., Cary, NC) was used for all analyses.

\section{Institutional Review Board Approval}

The study protocol was reviewed and approved by the Institutional Review Board of RTI International, and the Institutional Review Boards at both study universities.

\section{Results}

\section{Description of the Sample}

Table 1 shows that the majority of the women were non-Hispanic Whites. Somewhat more than half of the women were less than 21 years of age. Slightly more participants were enrolled at the Southeastern university. The sample included fairly similar numbers of freshmen, sophomores, juniors, and seniors. Extremely few respondents self-identified as being in a sexual minority group (Table 1 ). Of the 5,439 study women, 167 were bisexuals, 33 were lesbians, and 5,239 were heterosexuals.

\section{Women's Characteristics by Sexual Orientations}

Table 1 also shows that the women of different sexual orientations varied significantly in terms of their race/ethnicity, age, and university attended. Even though the sexual orientation groups differed by age, they did not differ significantly in terms of their year of study at university.

\section{Prevalence of Sexual Assault Before University by Sexual Orientation}

Analysis of data from the 167 bisexuals, 33 lesbians, and 5,239 heterosexuals showed that before entering university, bisexuals and lesbians experienced a significantly higher prevalence of sexual assault compared with heterosexuals $(25.4 \%$ of bisexuals, $22.4 \%$ of lesbians, and $10.7 \%$ of heterosexuals; Table 2 ). Compared with heterosexuals, the prevalence of sexual assault before university was 2.4 times higher (95\% CI, 1.8-3.1) 
Table 1. Characteristics of the 5,439 Study Women by their Sexual Orientations

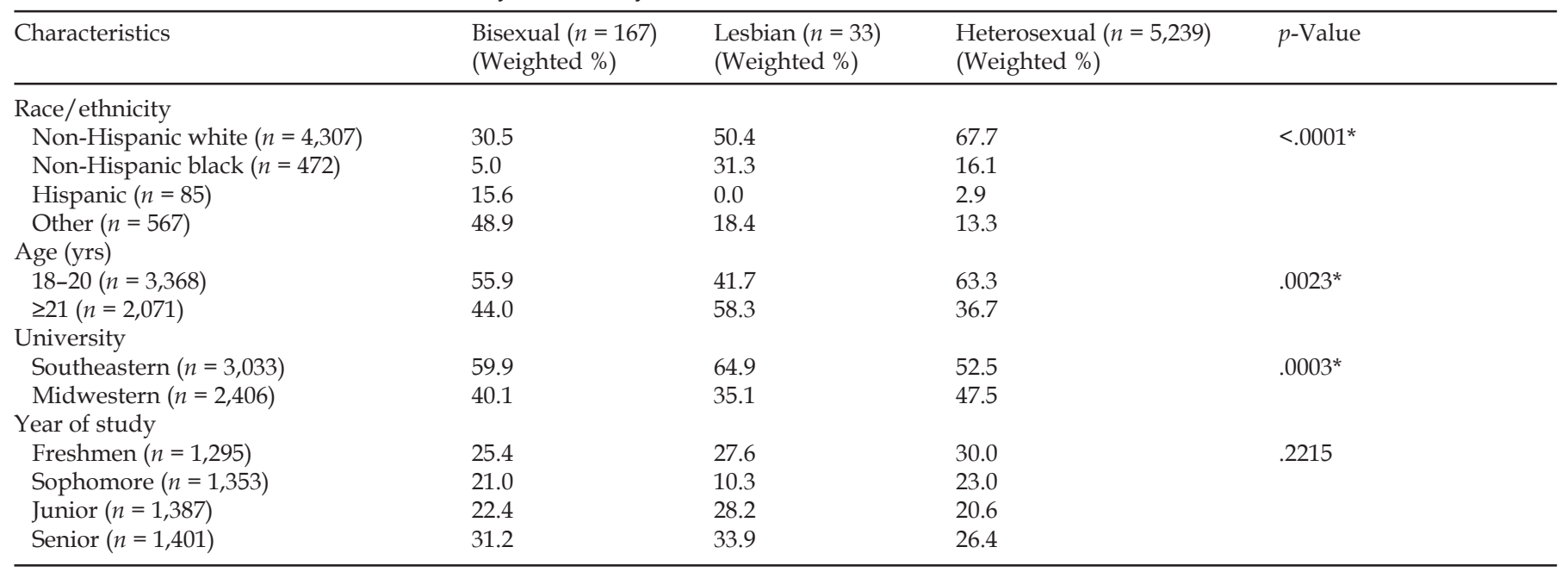

$n=$ the actual number of participants in each group (not weighted for non-response); weighted $\%=$ the percentage of participants per group, weighted for non-response. The column percentages may not sum to exactly $100 \%$ due to rounding. Sample sizes vary somewhat due to missing data; 8 participants were missing race/ethnicity data and 3 participants were missing information for their year of study.The $p$-values are based on Pearson chi-square tests for categorical variables.

${ }^{*} p<0.05$

among bisexuals and was 2.1 times higher (95\% CI, 1.1-4.0) among lesbians. Moreover, bisexuals and lesbians experienced a significantly higher prevalence of both physically forced and incapacitated sexual assault before university compared with heterosexuals.

\section{Prevalence of Sexual Assault During University by Sexual Orientations}

Somewhat similar sexual assault patterns were seen during university (Table 2), with $24.0 \%$ of bisexuals and $17.9 \%$ of lesbians being sexually assaulted during university compared with $13.3 \%$ of heterosexuals. The prevalence of sexual assault during university was significantly higher among bisexuals than heterosexuals (prevalence ratio, 1.8; 95\% CI, 1.4-2.4) and was elevated among lesbians compared with heterosexuals, although this difference was not significant (prevalence ratio, 1.4; 95\% CI, 0.7-2.8). Both bisexuals and lesbians experienced a higher prevalence of both physically forced and incapacitated sexual assault during university compared with heterosexuals; three of these four comparisons were significant.

\section{Sexual Assault Before University as a Predictor of Sexual As- sault During University}

Bisexuals, lesbians, and heterosexuals were significantly more likely to experience sexual assault during university if they had experienced sexual assault before university; thus, an early experience of sexual assault was positively associated with revictimization. Figure 1 shows that $49.9 \%$ of bisexuals sexually assaulted before university were also sexually assaulted during university, whereas only $15.2 \%$ of bisexuals not sexually assaulted before university were sexually assaulted during university $(z=7.44 ; p<.0001)$. Similarly, $59.8 \%$ of lesbians sexually assaulted before university were also sexually assaulted during university, whereas only $5.8 \%$ of lesbians not sexually assaulted before university were sexually assaulted during university $(z=$ 5.08; $p<0.0001$; note that this association should be interpreted with caution because of the small sample size). Among heterosexuals sexually assaulted before university, 32.9\% also were sexually assaulted during university; however, only $10.9 \%$ of heterosexuals not sexually assaulted before university were sexually assaulted during university $(z=27.12 ; p<.0001)$.

Table 2. Prevalence of Sexual Assault Before and During University by Sexual Orientations, and Prevalence Ratios Comparing the Extent of Sexual Assault Among Women of Differing Sexual Orientations

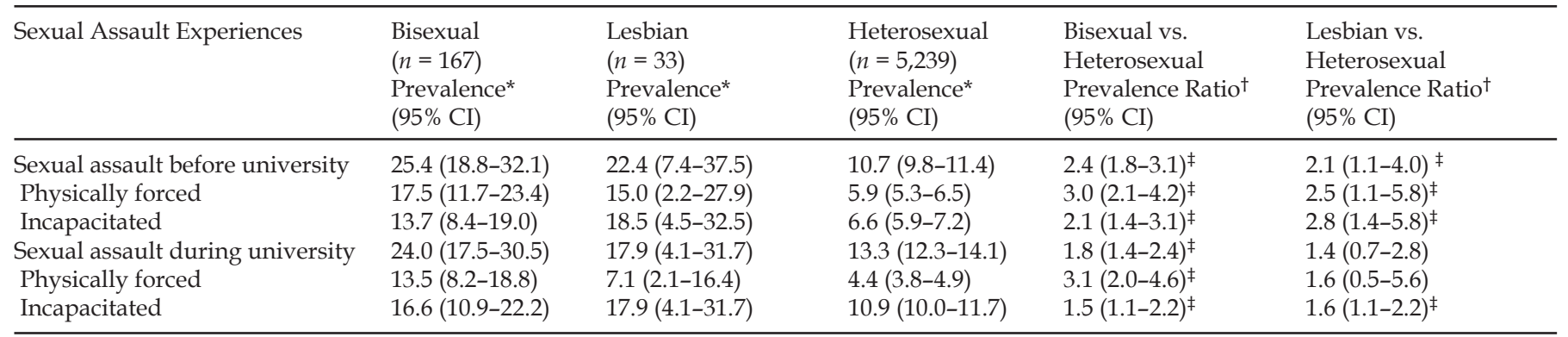

Some women experienced both physically forced and incapacitated sexual assault before university (11.1\% of lesbians, $5.8 \%$ of bisexuals, and $1.8 \%$ of heterosexuals), and some women experienced both physically forced and incapacitated sexual assault during university $(7.1 \%$ of lesbians, $6.1 \%$ of bisexuals, and $2.0 \%$ of heterosexuals).

* Prevalence estimates are weighted for nonresponse.

† Heterosexuals are used as the referent group in computation of the prevalence ratios.

$\ddagger p<0.05$. 


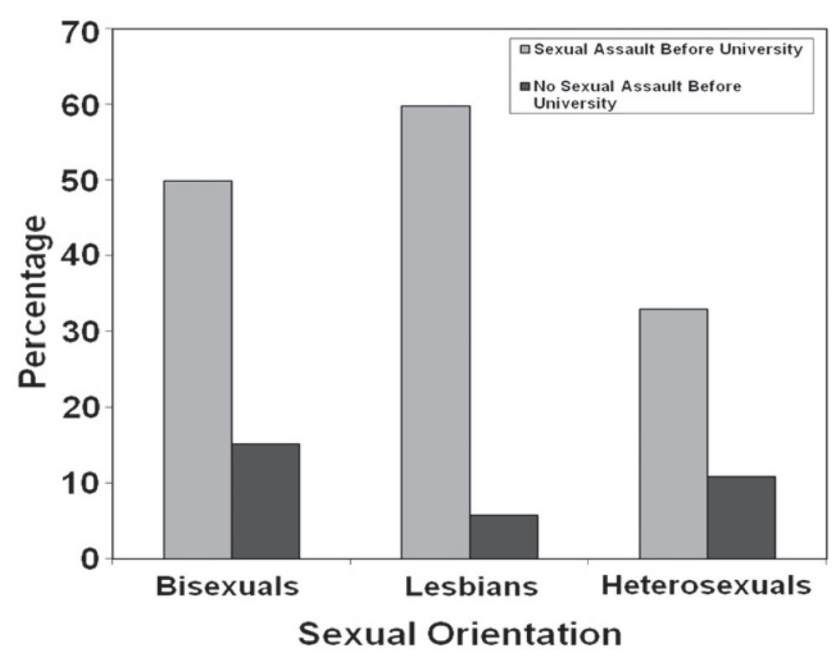

Figure 1. Percentages of women sexually assaulted during university, stratified by their sexual orientations and their experiences of sexual assault before university.

Table 3 presents the results of the logistic regression analysis. Compared with heterosexuals not sexually assaulted before university (the referent group), non-heterosexuals (bisexuals and lesbians) sexually assaulted before university had eight times the odds of being sexually assaulted during university (AOR, 8.75; 95\% CI, 5.18-14.80), whereas heterosexuals sexually assaulted before university had four times the odds of being sexually assaulted during university (AOR, 4.40; 95\% CI, 3.58-5.41). Although non-heterosexuals not sexually assaulted before university had a slightly increased odds of being sexually assaulted during university compared with heterosexuals who had not been sexually assaulted before university, this

Table 3. Results of the Logistic Regression Model of Sexual Assault During University as a Function of Sexual Orientation, Sexual Assault Before University, and Several Characteristics of the Women

\begin{tabular}{ll}
\hline Variables & Adjusted OR (95\% CI) \\
\hline $\begin{array}{l}\text { Bisexual or lesbian, sexually assaulted } \\
\text { before university }\end{array}$ & $8.75(5.18-14.80)^{*}$ \\
$\begin{array}{l}\text { Heterosexual, sexually assaulted before } \\
\quad \text { university }\end{array}$ & $4.40(3.58-5.41)^{*}$ \\
$\begin{array}{l}\text { Bisexual or lesbian, not sexually assaulted } \\
\text { before university }\end{array}$ & $1.34(0.86-2.08)$ \\
$\begin{array}{l}\text { Age ( } \geq 21 \text { years vs. 18-20 years as referent) } \\
\text { Year of study (junior/senior vs. }\end{array}$ & $1.69(1.28-2.27)^{*}$ \\
$\quad$ freshman/ sophomore as referent) & $1.45(1.09-1.89)^{*}$ \\
$\begin{array}{l}\text { University attending (Southeastern vs. } \\
\quad \text { Midwestern as referent) }\end{array}$ & $1.37(1.16-1.61)^{*}$ \\
$\begin{array}{l}\text { Race/ethnicity (non-Hispanic White vs. } \\
\text { all other racial/ethnic groups as referent) }\end{array}$ & $1.23(1.03-1.47)^{*}$ \\
\hline
\end{tabular}

The logistic regression analysis modeled women's experiences of any type of sexual assault during university (yes vs. no) as a function of women's sexual orientations and experiences of sexual assault before university (coded by the use of three indicator variables to denote the four groups of interest, namely, bisexuals and lesbians with sexual assault before university, bisexuals and lesbians without sexual assault before university, heterosexuals with sexual assault before university, and the referent group, namely, heterosexuals without sexual assault before university), university attended (Southeastern vs. Midwestern as the referent group), year of study (junior or senior vs. freshman or sophomore as the referent group), age ( $\geq 21 \mathrm{vs.} 18-20$ as the referent group) and race/ethnicity (non-Hispanic White vs. all other racial/ethnic groups as the referent group).

${ }^{*} p<.05$. difference was not significant (AOR, 1.34; 95\% CI, 0.86-2.08). Control variables associated with sexual assault during university included being older, more advanced in university tenure, enrolled in the Southeastern university, and non-Hispanic White.

\section{Discussion}

These results are consistent with past studies in finding that previous sexual assault is a strong predictor of sexual revictimization (Breitenbecher, 2001), and that students in sexual orientation minority groups are more likely than heterosexual students to be sexually assaulted during university (Duncan, 1990; Rothman and Silverman, 2007). These results extend past research by suggesting that much of the observed difference in the prevalence of sexual assault during university between non-heterosexual women and heterosexual women may be attributable to non-heterosexuals' increased prevalence of sexual assault before university. In this study, bisexuals and lesbians had twice the odds of heterosexuals of having been sexually assaulted before coming to university, and women of all sexual orientations were much more likely to be sexually assaulted during university if they had been sexually assaulted before university. Bisexuals and lesbians who had not been sexually assaulted before entering university had similar odds of sexual assault during university as heterosexuals who had not been sexually assaulted before university, which highlights the role of prior sexual assault as a risk factor for subsequent sexual assault. Thus, the question arises as to why bisexuals and lesbians experience higher rates of sexual assault before university than do heterosexuals. Although the current study cannot address this important question, past research has found that bisexual and lesbian women have elevated rates of childhood sexual, physical, and emotional abuse relative to heterosexual women, including sexual molestation by their mothers and other females (Balsam et al., 2005; Tomeo et al., 2001). Moreover, research has linked these traumatic early childhood experiences with an increased likelihood of sexual revictimization during later childhood, adolescence and early adulthood (Descemps et al., 2000; Heidt et al., 2005).

Caution is urged in interpreting these study results because of the methodologic limitations of the research. First, as with many web-based surveys (Cook, Health, \& Thompson, 2000), the CSA study had a relatively low response rate; however, adjusting the study findings to take the characteristics of the responders and non-responders into account may have helped to diminish potential nonresponse bias. Another study limitation is that the samples of bisexuals and lesbians were fairly small, which restricted the statistical power of some analytic procedures; however, it is important to note that many of the analyses focused on these groups documented large and significant effect sizes. An additional study concern is that some persons may be reluctant to disclose sexual assault experiences, resulting in underestimating the extent of sexual assault; however, the use of an anonymous, web-based survey may have helped to overcome this problem. Another potential study problem is that, although the prevalence estimates for each type of sexual orientation examined in this research are similar to those found in a nationally representative sample of 18- to 26-year-old women, the national study showed that, for a small percentage of persons, sexual orientation changes over time (Savin-Williams and Ream, 2007; Diamond, 2008). Therefore, some of the CSA study respondents may have had a different sexual orientation before participating in the CSA study that would have 
resulted in our misclassification of their sexual orientation in the analyses focused on the time period before entering college. Moreover, the survey did not ask about the gender (male/female) of the perpetrators, data that would have helped to inform the study findings.

An important question one might pose is whether the study findings may be, at least part, attributable to differences in students' levels of awareness of sexual violence issues (such as nonconsensual/unwanted sexual contact), with more aware students being more likely than less aware students to label particular acts as sexual assault, resulting in their increased reporting of such experiences. There may well be differences in such awareness within university populations; however, this study's use of behaviorally specific phrasing to ask about nonconsensual/unwanted sexual contact (e.g., asking about forced touching, oral sex, vaginal sexual intercourse, anal sexual intercourse, and vaginal or anal penetration with a finger/object), rather than less behaviorally specific phrasing (e.g., asking about rape), limits this potential bias by promoting equivalent understanding and interpretation of the questions among all groups of women.

The research findings presented here have implications for sexual assault prevention and intervention strategies. Coupling prevalence findings showing that many girls and adolescent women are sexually victimized before entering university with the growing evidence that sexual assault takes a negative toll on survivors' psychological and physical wellbeing, it is clear that efforts focused on the primary prevention of sexual assault of children and adolescents should be enhanced. This means directing more primary prevention efforts on the potential perpetrators of such crimes. In addition, teachers, pediatricians, and other service professionals should educate young people and their parents about sexual assault and risk reduction, with such messages being tailored to take into consideration the developmental age and sexual orientation of the audience (Frankowski \& the Committee on Adolescence, 2004). Not only would effective primary prevention efforts decrease the burden of suffering among the young, but it would likely result in a lowering of the prevalence of sexual assault in later years given that early sexual assault is such a strong risk factor for later sexual assault. Moreover, the continuation of sexual violence prevention programs within university settings is encouraged, with the choice of programs being based on empirical assessments of the program's effectiveness, and with the educational materials/services being culturally competent and tailored for persons of various sexual orientations (Gentlewarrior, 2009; Rothman and Silverman, 2007). Such approaches could help to prevent future sexual assaults, and they also could increase sexual assault survivors' willingness to report their experiences to relevant authorities and to seek therapeutic services so they do not suffer in silence and isolation.

Acknowledgments - Financial support for this research was provided by Grant Number 2004-WG-BX-0010, awarded by the National Institute of Justice, Office of Justice Programs, U.S. Department of Justice.

The views presented in this work do not necessarily represent the official position or policies of the U.S. Department of Justice. The authors thank the administrators and students of the two participating universities for their support and involvement in this study, as well as Dr. Lawrence L. Kupper, Alumni Distinguished Professor of Biostatistics at the University of North Carolina at Chapel Hill, who provided guidance on the statistical analyses. The PI of the project that funded this work, Dr. Christopher Krebs, had full access to all the data in this study and takes responsibility for the integrity of the data and the accuracy of the data analysis. There are no conflicts of interest.

\section{References}

Balsam, K. F., Rothblum, E. D., \& Beauchaine, T. P. (2005). Victimization over the life span: A comparison of lesbian, gay, bisexual and heterosexual siblings. Journal of Consulting and Clinical Psychology, 73, 477-487.

Banyard, V., Ward, S., Cohn, E. S., Plante, E. G., Moorhead, C., \& Walsh, W. (2007). Unwanted sexual contact on campus: A comparison of women's and men's experiences. Violence and Victims, 22, 52-70.

Bonomi, A. E., Anderson, M. L., Rivara, F. P., \& Thompson, R. S. (2007). Health outcomes in women with physical and sexual intimate partner violence exposure. Journal of Women's Health, 16(7), 987-997.

Breitenbecher, K. H. (2001). Sexual revictimization among women: a review of the literature focusing on empirical investigations. Aggression and Violent Behavior, 6, 415-432.

Campbell, R., \& Wasco, S. M. (2005). Understanding rape and sexual assault. Journal of Interpersonal Violence, 20, 127-131.

Cohen, J. (1988). Statistical power analysis for the behavioral sciences (2nd ed.). Hillsdale, NJ: Lawrence Erlbaum Associates.

Cook, C., Health, F., \& Thompson, R. L. (2000). A meta-analysis of response rates in web- or internet-based surveys. Educational and Psychological Measurement, 60, 821-836.

Demaris, A., \& Kaukinen, C. (2005). Violent victimization and women's mental and physical health: Evidence from a national sample. Journal of Research in Crime and Delinquency, 42, 384-411.

Descemps, M. J., Rothblum, E., Bradford, J., \& Ryan, C. (2000). Mental health impact of child sexual abuse, rape, intimate partner violence, and hate crimes in the national Lesbian Health Care Survey. Journal of Gay and Lesbian Social Services, 11, 27-55.

Diamond, L. M. (2008). Sexual fluidity: Understanding women's love and desire. Cambridge, MA: Harvard University Press.

Dunbar, E. (2006). Race, gender, and sexual orientation in hate crime victimization: Identity politics or identity risk? Violence and Victims, 21, 323-337.

Duncan, D. E. (1990). Prevalence of sexual assault victimization among heterosexual and gay/lesbian university students. Psychological Reports, 66, 65-66.

Fisher, B. S., Cullen, F. T., \& Turner, M. G. (2000). The sexual victimization of college women. Washington, DC: U.S. Department of Justice, Office of Justice Program.

Folsom, R. E., \& Singh, A. C. (2000). The generalized exponential model for sampling weight calibration for extreme values, non-response, and poststratification. Paper presented at the American Statistical Association Meeting, Proceedings of the Section on Survey Research Methods of the American Statistical Association.

Frankowski, B., \& , the Committee on Adolescence. (2004). Sexual orientation and adolescents: American Academy of Pediatrics clinical report guidance for the clinician rendering pediatric care. Pediatrics, 113, 1827-1832.

Gentlewarrior, S. (2009). Culturally competent service provision to lesbian, gay, bisexual and transgender survivors of sexual violence. Applied Research Form, National Online Resource Center on Violence Against Women. Available: www.vawnet.org. Accessed September 2009.

Greenwood, G. L., Relf, M. V., Huang, B., Pollack, L. M., Canchola, J. A., \& Catania, J. A. (2002). Battering victimization among a probability-based sample of men who have sex with men. American Journal of Public Health, 92, 1964-1969.

Heidt, J. M., Marx, B. P., \& Gold, S. D. (2005). Sexual revictimization among sexual minorities: A preliminary study. Journal of Traumatic Stress, 18, 533-540.

Heintz, A. J., \& Melendez, R. M. (2006). Intimate partner violence and HIV/STD risk among lesbian, gay, bisexual, and transgender individuals. Journal of Interpersonal Violence, 21(2), 193-208. 
Herek, G. M. (1993). Documenting prejudice against lesbians and gay men on campus: The Yale Sexual Orientation Survey. Journal of Homosexuality, 25, 15-30.

Houston, E., \& McKirnan, D. J. (2007). Intimate partner abuse among gay and bisexual men: Risk correlates and health outcomes. Journal of Urban Health: Bulletin of the New York Academy of Medicine, 84, 681-690.

Howard, D. E., Griffin, M. A., \& Boekeloo, B. O. (2008). Prevalence and psychosocial correlates of alcohol-related sexual assault among university students. Adolescence, 43(172), 733-750.

Hughes, T. L., Szalacha, L. A., Johnson, T. P., Kinnison, K. E., Wilsnack, S. C., \& Cho, Y. (2010). Sexual victimization and hazardous drinking among heterosexual and sexual minority women. Addictive Behaviors, 35, 1152-1156.

Kilpatrick, D. G., Resnick, H. S., Ruggiero, K. J., Conoscenti, L. M., \& McCauley, J. (2007). Drug-facilitated, incapacitated, and forcible rape: A national study. Charleston, SC: National Crime Victims Research and Treatment Center.

Kimerling, R., Rellini, A., Kelly, V., Judson, P. L., \& Learnman, L. A. (2002). Gender differences in victim and crime characteristics of sexual assaults. Journal of Interpersonal Violence, 17, 526-532.

Krebs, C. P., Lindquist, C. H., Warner, T. D., Fisher, B. S., \& Martin, S. L. (2007). The Campus Sexual Assault (CSA) study: final report (Document 221153). Washington, DC: U.S. Department of Justice.

Krebs, C. P., Lindquist, C. H., Warner, T. D., Fisher, B. S., \& Martin, S. L. (2009a). College women's experiences with physically forced, alcohol- or other drugenabled, and drug-facilitated sexual assault before and since entering college. Journal of College Health, 57, 639-647.

Krebs, C. P., Lindquist, C. H.,Warner, T. D., Fisher, B. S., \& Martin, S. L. (2009b). The differential risk factors of physically forced and alcohol or other drug enabled sexual assault among university women. Violence and Victims, 24, 302-320.

Long, S. M., Ullman, S. E., Long, L. M., Manson, G. E., \& Starznski, L. L. (2007). Women's experiences of male-perpetrated sexual assault by sexual orientation. Violence and Victims, 22, 684-701.

Martin, S. L., Macy, R. J., \& Young, S. K. (2011). Chapter 8, Health and economic consequences of sexual violence. In J. W. White, M. P. Koss, \& A. E. Kazdin (Eds.), Violence against women and children: Mapping the terrain, Volume I (pp. 173-195). Washington, DC: American Psychological Association.

Martin, S. L., Rentz, E. D., Chan, R. L., Givens, J., Sanford, C. P., Kupper, L. L., et al. (2008). Physical and sexual violence among North Carolina women: Associations with physical health, mental health, and functional impairment. Women's Health Issues, 18. 130-130.

Mohler-Kuo, M., Dowdall, G. W., Koss, M. P., \& Wechsler, H. (2004). Correlates of rape while intoxicated in a National Sample of College Women. Journal of Studies on Alcohol, 65, 37-45.

Ratner, P. A., Johnson, J. L., Shoveller, J. A., Chan, K., Martindale, S. L., \& Schilder, A. J. (2003). Non-consensual sex experienced by men who have sex with men: Prevalence and association with mental health. Patient Education and Counseling, 49, 67-74.

Rothman, E., \& Silverman, J. (2007). The effect of a college sexual assault prevention program on first-year students' victimization rates. Journal of American College Health, 55, 283-290.

Samandari, G., \& Martin, S. L. (2010). Victimization of gay, lesbian, bisexual and transgendered individuals. In B. S. Fisher, \& S. P. Lab (Eds.), Encyclopedia of victimology and crime prevention (427-429). Thousand Oaks, CA: Sage.
Savin-Williams, R. C., \& Ream, G. L. (2007). Prevalence of sexual orientation components during adolescence and young adulthood. Archives of Sexual Behavior, 36, 385-394.

Stockman, J. K., Campbell, J. C., \& Celentano, D. D. (2010). Sexual violence and HIV risk behaviors among a nationally representative sample of heterosexual American women: The importance of sexual coercion. Journal of Acquired Immune Deficiency Syndromes, 53, 136-143.

Sugar, N., Fine, D., \& Eckert, L. (2004). Physical injury after sexual assault: Findings of a large case series. American Journal of Obstetrics and Gynecology, 190, 71-76.

Thompson, M. L., Myers, J. E., \& Kriebel, D. (1998). Prevalence odds ratio or prevalence ratio in the analysis of cross sectional studies. Occupational Environmental Medicine, 55, 272-277.

Tjaden, P., \& Thoennes, N. (2000). Full report of the prevalence, incidence, and consequences of violence against women: Findings from the violence against women survey. Washington, DC: U.S. Department of Justice.

Tomeo, M. E., Templer, D. I., Anderson, S., \& Kotler, D. (2001). Comparative data on childhood and adolescent molestation in heterosexual and homosexual persons. Archives of Sexual Behavior, 30, 535-541.

\section{The Authors}

Sandra L. Martin is an epidemiologist and Professor in the Department of Maternal and Child Health, University of North Carolina, Chapel Hill. Her research, teaching and service activities focus on physical and sexual violence in women's lives.

Bonnie S. Fisher received her PhD from Northwestern University and is a Professor at the University of Cincinnati. She coauthored Unsafe in the Ivory Tower: The Sexual Victimization of College Women. Her research includes evaluating effectiveness of bystander interventions among college students.

Tara D. Warner is a doctoral student in Sociology at Bowling Green State University. Her research focuses on how structural and cultural contextual factors impact individuals' behavior, health, and well-being, with a particular focus on adolescence and emerging adulthood.

Christopher P. Krebs received his $\mathrm{PhD}$ in Criminology from Florida State University and is a senior research sociologist at RTI. His research interests include drug epidemiology and treatment, intimate partner violence and sexual violence, criminal justice systems, and program evaluation.

Christine H. Lindquist received her PhD in Medical Sociology from the University of Alabama, Birmingham and is a senior research sociologist at RTI. Her research interests and areas of expertise include prisoner reentry, families and incarceration, and violence against women. 